\title{
The knowledge of lexical collocation among university students and its relation to their speaking proficiency
}

\author{
ARIFUDDIN ABDULLAH ${ }^{1, a^{*}}$, ROZINA ABDUL GHANI $^{2, b}$, SOO-YIN SEE ${ }^{1, c}$
}

\author{
${ }^{1}$ Centre for Language Studies and Generic Development, Universiti Malaysia Kelantan, Kelantan, \\ Malaysia \\ ${ }^{2}$ Kulliyyah of Islamic Revealed Knowledge and Human Sciences, International Islamic University \\ Malaysia, Malaysia \\ Corresponding Author: aarifuddin@umk.edu.my, brozina@iium.edu.my, 'see@umk.edu.my
}

Keywords: Collocational competence, lexical collocation, speaking proficiency, lexical collocation test, speaking proficiency test

\begin{abstract}
This study aims to investigate students' collocational competence by examining the relationship between the knowledge of lexical collocation among them. The respondents were 30 students of Universiti Malaysia Kelantan (UMK). A lexical collocation test (LCT) was constructed to gauge the knowledge of collocation, while a speaking proficiency test (SPT) adopted from the IELTS was administered to determine the students' level of speaking proficiency. Both variables were then correlated. The result indicates that there was no significant correlation between the knowledge of collocation and speaking proficiency among the respondents. Based on the findings, it is revealed that exposure to the target language plays a vital role in language acquisition. Exposure to collocations in particular would enable the learners to speak more fluently and sound more native-like.
\end{abstract}

\section{INTRODUCTION}

The ultimate goal of learning a language is to be able to communicate effectively. In realizing communicative competence, comprehensibility of a speaker's speech production must be taken into account. As a rule of thumb, it is essential for non-native speakers to emulate the way native speakers use their language as a benchmark in reaching that goal. Native-like competence is characterized by speakers' ability to use a target language in a way that is natural and considered acceptable by the native speakers. It is one of the features of this native-likeness. Collocation is made up of word combinations which are naturally and frequently used by native speakers. Collocation plays an important role in language acquisition as it helps learners improve their communication skills and also helps them achieve native-like competence $[11,13]$. Collocation along with other types of prefabricated chunks or ready-made expressions consisting of word combinations that are repeatedly used by native speakers is said to contribute $58.6 \%$ and $52.3 \%$ to the composition of both their spoken and written discourses respectively [7]. This is reflective of the significance of acquiring word combinations in order to achieve the level of language competence of the native speakers of the target language. Along the same line, Schmitt (2004) reports that these formulaic sequences are extensively used in discourse and set the non-native speakers apart from native speakers in language proficiency.

The level of English proficiency among UMK students still leaves a lot to be desired and deserves considerable attention. Their performance in the university English papers and Malaysian University English Test (MUET) often demonstrates some problems. One of the difficulties which could be identified besides poor grammar is students' struggle in producing acceptable word combinations or collocations, which is deemed vital for them to acquire a good command of English. These word combinations which are considered part of lexical chunks will help learners engage in communication more effectively and fluently [12]. Similarly, Hill (2000) maintains that one of the main reasons leading to students' poor command of English, is the lack of collocational competence. Collocational competence refers to one's knowledge and use of collocation 
appropriately as used by the native speakers of English. Hill's statement is true as students would resort to constructing their own utterances when they do not know how these utterances are precisely produced in a target language. Consequently, this lack of competence would result in erroneous utterances alien to native speakers' ears due to incorrect lexical choice.

The understanding of issues concerning collocational competence in speaking proficiency is substantial to English language teaching and learning at UMK in particular and the Malaysian context in general as it will offer insights into students' problems in the area of vocabulary acquisition and their speaking performance. If the findings demonstrate that students' lexical collocation competence contributes to higher speaking proficiency, a shift in teaching methods emphasizing collocations might be relevant and should be implemented accordingly. This study also aims to shed light on our understanding of the roles of memory, lexis and chunking in acquiring a language. Lexis in particular is considered to be the key principle to the process. It is believed that the mastery of word combinations or chunks of words retained in the memory contribute to language fluency. In addition, as the study is situated in a local setting, it is indeed a contribution to the existing research of this area of vocabulary and its profound effect on both second language and foreign language acquisition

There has been a lot of research emphasising the importance of collocation in English language proficiency among second language learners [2, 5, 8, 10, 18]. However, most of these studies have focused on writing skills rather than other language skills such as speaking, listening and reading. In addition, the types of collocations tested are limited to one to two categories of both lexical and grammatical collocations. Therefore, this study aims at adding more empirical evidence on collocation among ESL and EFL students. It explores lexical collocation in speaking proficiency by including all of its categories in order to better understand its importance especially in this particular area of language skills. In sum, this study aims to further examine the relationship between collocational competence (lexical collocations of different categories) and speaking proficiency among the participants.

\section{METHODOLOGY}

\subsection{Research Design}

This study employed both quantitative and qualitative methods of research. O'Leary (2010) mentions that by adopting this mixed method, a study could add more value as it allows more than one perspective of looking at a particular situation. The qualitative analysis was used to examine the degree to which knowledge of lexical collocation is related to speaking proficiency. The findings for this research question were presented in the form of a descriptive statistic. Respondents' knowledge of collocation was measured based on their scores on the Lexical Collocation Test (LCT), while their speaking proficiency was assessed and given scores to see whether a relationship existed between these two variables. To score the respondents' speaking proficiency, the Speaking Proficiency Test (SPT) was used.

\subsection{Setting}

The study was conducted at Jeli campus of Universiti Malaysia Kelantan (UMK) located in the state of Kelantan. It is a public university with entrepreneurship as a core trust. This university consists of three campuses. Each campus specialises in different programmes. Pengkalan Chepa campus, also called city campus offers business and entrepreneurship-based programmes; Bachok campus caters for arts and heritage programmes, while Jeli campus offers science programmes. All of these programmes have been designed to equip the students with entrepreneurial qualities. In addition, although it is not a requirement, most of the courses are taught in English. Given the importance of English, the university is moving toward gradually implementing the language as the medium of instruction for all programmes. Besides, UMK students are also required to take a national English test for university entry, called the Malaysian University English Test (MUET) and also university English courses comprising three levels of proficiency which are English I 
(Foundation), English II (Intermediate), English III (English for Specific Purposes). MUET consists of four parts covering the four languages skills; listening, speaking, reading and also writing. Students who score Band 2 and below are required to take English I to provide them with basic knowledge of the English language. Those with Band 3 and above are exempted from taking English I. However, all students must take English II and English III. These courses are made compulsory for all students.

\subsection{Respondents}

A number of 30 third year Malay students of Universiti Malaysia Kelantan (UMK) were selected for this study. The respondents comprising fifteen male and fifteen female students were selected by means of convenient sampling with a few criteria taken into consideration. All the respondents studied at the Faculty of Earth Science, UMK Jeli campus and had already taken all three university English courses and prior to that had sat for MUET. The selected respondents also underwent eleven years of formal English learning within the Malaysian education system. With a learning span of over ten years, they were expected to exhibit a certain degree of English language proficiency and knowledge of collocation.

\subsection{Instruments}

This study used two types of instruments for the purpose of data collection, namely the Lexical Collocation Test (LCT) and the Speaking Proficiency Test (SPT).

\subsubsection{Lexical Collocation Test (LCT)}

This written test comprises two parts and aims to measure the respondents' knowledge of lexical collocation (refer to Appendix A). The first part is a set of demographic questions designed to elicit their background information. The second part comprises six sections of gap-filling questions on all types of lexical collocation, containing nine to ten questions each. These types were adapted from the BBI Combinatory Dictionary of English (Verb+Noun, Adjective+Noun, Noun+Verb, Noun1+of+Noun2, Adverb+Adjective and Verb+Adverb) [4]. In the dictionary, the Verb+Noun type is divided into two subtypes. One is to denote creation and/or activation and the other one is eradication and/or nullification. However, in this study, the two types of the Verb+Noun category were combined in one section. This is to limit the respondents' consumption of time when attempting this test.

Questions for the Verb+Noun and Adjective+Noun of lexical collocation were adopted and adapted from Alsakran (2011) and the rest of the categories were examples of collocations taken from Oxford Collocation Dictionary (2009) and Lewis's (2000) collection of collocation exercises in his book entitled "Teaching Collocation Further Developments in the Lexical Approach". The number of questions for the Adjective+Noun category was reduced to nine, because one of them was omitted subsequent to the pilot study due to misconstruction. Due to the amount of time taken to finish the test, the researcher decided not to replace it with a new question. In addition, the reduction in the amount of questions does not affect the results as they are presented statistically in percentages. All the collocations used in the questions were frequently used in English. This was confirmed with the help of a native speaker. It is useful to take native speakers' intuition into consideration in determining the use of English language. This test was also constructed in a way that allows only one answer for each question. The first letter of the collocation was given as a clue to avoid guessing and to direct the respondents to the answers. When students possess the knowledge of collocation, it was assumed that they could easily answer the questions by considering the clues given and the word combined with it. 


\subsubsection{Speaking Proficiency Test (SPT)}

The IELTS speaking proficiency test was used to measure the respondents' speaking proficiency (refer to Appendix B). The IELTS test was chosen as it is well established and used by many institutions to measure learner's English language proficiency. This test consists of three parts. The respondents were required to descriptively respond to the stimuli given. The first part consisted of a brief introduction by the examiner and an icebreaker session with the respondents. They were asked to describe their hometown and the accommodation they live in. For that purpose, a number of questions directed to the topic were given as prompts. In the second part, the respondents were asked to talk about something they own that is important to them. This session required them to describe the item and elaborate on it as much as possible. Before the session began, the respondents were asked to it on paper first before they explained it to the examiner. To round off the session, the respondents were asked two questions related to the discussion. The third part involved a two-way discussion about more thoughtful topics. The respondents were asked to respond to questions on the value and role of advertising. It was assumed that questions on this topic would help prompt them to produce lexical phrases including collocation, as the topic given was largely descriptive in nature. Besides, the use of lexical resources was one of the scoring criteria; hence, it is presupposed that the test was well designed so that test takers would produce as many lexicons as possible including collocations.

\subsection{Data Collection}

The respondents were asked to sit for two types of tests. First of all, they took the Lexical Collocation Test (LCT) to measure students' knowledge of collocation. This test was designed based on Benson et al.'s (1986) framework of lexical collocation. Second, the respondents took the Speaking Proficiency Test (SPT) based on the IELTS speaking test. This framework was chosen because it is the most adapted classification of collocation among researchers $[2,10,17]$. The gapfilling questions in LCT were scored as either correct, incorrect or no answer, because the questions permit only one possible answer. During the SPT, on the other hand, each respondent was given fifteen minutes to talk about the same topic. A recorder was used to record the interaction between the respondents and the raters. The transcriptions of the recordings can be found in Appendix C. Two raters from Universiti Malaysia Kelantan (UMK) who were well-versed in speaking skills assisted with the test assessment. This was to ensure the reliability of the scoring and to reduce bias. The scoring rubric used for the evaluation was the IELTS Speaking Band Descriptors. This scoring method is based on banding which begins from Band 1 until 9. However, in this study, the IELTS scoring rubric was revised to only represent three levels of proficiency: (1) Low, (2) Moderate and (3) High. The classification into the three main levels was meant to facilitate the scoring and the data presentation. This was done with the help of colleagues who were experts in language testing.

\subsection{Data Analysis}

All the data was coded and all the tests were placed in folders and identified by a number. Each respondent was identified using the same method. The respondents' performances in LCT and SPT were the correlated and analysed using Pearson's Product Moment Correlation Coefficient of the Statistical Package for Social Science (SPSS version 16.0 for Windows) software. As for the SPT, the test was recorded and transcribed before undertaking a close analysis of spoken data. The corpus was coded to analyse the use of collocation in terms of its frequency and types. The researcher used the Online British National Corpus (http://www.natcorp.ox.ac.uk/) and a native speaker assisted to evaluate the data to see whether the collocations used are acceptable and naturally used in English.

\section{RESULTS}

\subsection{Respondents' Demographic Data}

The respondents' demographic data comprise gender, age, state, programme, MUET result and language as shown in Table $\mathbf{1 .}$ 
Table 1. Demographic data of the population participating in this study

\begin{tabular}{|ll|c|c|}
\hline Item & Frequency $(n)$ & Percentage (\%) \\
\hline Gender: & 15 & \\
& Male & 15 & 50.0 \\
& Female & 30 & 50.0 \\
& Total & & 100.0 \\
\hline Age: & & 2 & \\
& Below19 & 28 & 6.7 \\
& $20-24$ & 30 & 93.3 \\
& Total & & 100.0 \\
\hline State: & & 3 & \\
& Johor & 7 & 10.0 \\
& Selangor & 4 & 23.3 \\
& Perak & 1 & 13.3 \\
& Negeri Sembilan & 8 & 3.3 \\
Kelantan & 3 & 26.7 \\
& Pahang & 1 & 10.0 \\
Kuala Lumpur & 2 & 3.3 \\
Kedah & 1 & 6.7 \\
Terengganu & 30 & 3.3 \\
Total & & 100.0 \\
\hline Programme of Study: & 30 & \\
Faculty of Earth Science & & 100.0 \\
\hline Muet: & Band 2 & 3 & 10.0 \\
Band 3 & 24 & 80.0 \\
Band 4 & 3 & 10.0 \\
Total & 30 & 100.0 \\
\hline
\end{tabular}

There were 30 students involved in this study, comprising 50\% $(n=15)$ male and $50 \%(n=$ 15) female respondents. 93.3\% of them aged between 20-24 years old and 6.7\% aged below 19 years old. All respondents were Malays from different states. The majority of them came from Kelantan (26.7\%), followed by Selangor (23.2\%) and Perak (13\%). All of the respondents studied at the same faculty, namely the Faculty of Earth Science. $80 \%$ of the respondents in this study obtained Band 3 in MUET. The remaining 20\% were Band 2 and 4 achievers, accounting for 10\% each. According to the grading system, those with a Band 3 score are considered having a modest command of the English language. Band 4 scores are given to proficient speakers and Band 2 achievers have a limited grasp of English.

The respondents were also questioned about their English language use and learning, as well as their exposure to the language. The results are demonstrated in Table 2. When asked what language they spoke daily, $63.3 \%$ of them stated that they used Malay while another $36.7 \%$ used a mix of Malay and English. On language(s) spoken at home, more than $90 \%$ spoke Malay as their first language. Only a handful of the respondents (6.7\%) used a mix of Malay and English at home as a medium of interaction. The respondents were also asked about the period of time they spent learning English. Since all of them underwent the same education system, they had been learning the language for more than 10 years. In Malaysia, English language learning formally commences from the start of primary school up until the tertiary level. 
Table 2. Respondents' exposure to English

\begin{tabular}{|l|c|c|}
\hline Item & Frequency $(n)$ & Percentage (\%) \\
\hline Language students speak daily: & & \\
Malay & 19 & 63.3 \\
A mix of Malay and English & 11 & 36.7 \\
Total & 30 & 100.0 \\
\hline Language(s) spoken at home: & 28 & \\
Malay & 2 & 93.3 \\
A mix of Malay and English & 30 & 6.7 \\
Total & 30 & 100.0 \\
\hline Period of time learning English: & 30 & 100.0 \\
< 10 years & & 100.0 \\
Total &
\end{tabular}

\subsection{The relationship between students' knowledge of lexical collocation and their speaking proficiency}

To examine the association between students' knowledge of lexical collocation and speaking proficiency, the scores of both tests were calculated using Pearson's correlation. The scores of Lexical Collocation Test (LCT) were calculated, based on the number of correct answers. Meanwhile, student's performance in speaking was based on scores of Speaking Proficiency Test (SPT). The average scores of two raters were taken as the final score. Prior to that, inter-rater reliability test using Cronbach's alpha was administered and it was found that the two raters' scores had a reliability of 0.963 . In addition, the findings showed (as indicated in Table 3 ) that the mean and standard deviation for LCT for the 30 respondents was 28.58 and 7.89 respectively, and SPT had a mean of 5.64 and the standard deviation was 0.81 .

Table 3. Respondents' mean scores on LCT and SPT

\begin{tabular}{|c|c|c|c|}
\hline Test Type & $n$ & Mean & Std. Deviation \\
\hline LCT & 30 & 28.58 & 7.89 \\
\hline SPT & 30 & 5.64 & 0.81 \\
\hline
\end{tabular}

The results showed that there was no significant relationship between respondents' knowledge of collocation and speaking proficiency $(n=30, \mathrm{r}=.192, \mathrm{p}>0.05)$.

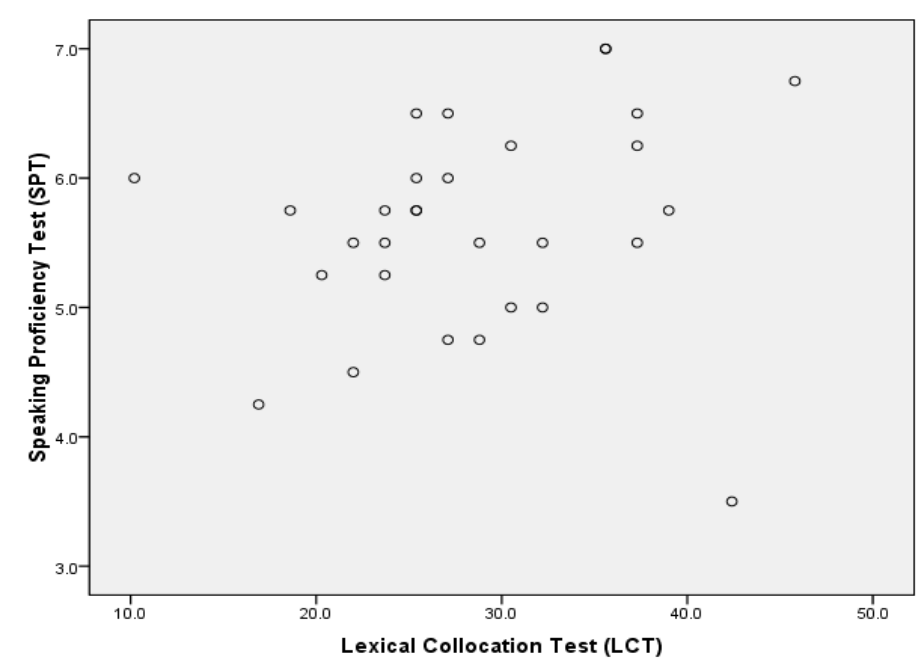

Figure 1. Relationship between respondents' collocational competence (LCT) and Speaking Proficiency Test (SPT) 
Besides, based on the analysis presented in Table 4, none of the respondents were able to obtain more than $50.0 \%$ of the total score. Both male and female's performances in LCT were almost equal, with a mean of 29.2 for male respondents and 28.0 for female respondents. They also shared the same mean score for SPT, which was 6.

Table 4. Distribution of SPT and LCT Scores

\begin{tabular}{|c|c|c|c|c|c|}
\hline Gender & Respondent & SPT score (Average) & LCT score $(\%)$ & $\begin{array}{l}\text { SPT mean } \\
\text { score }\end{array}$ & $\begin{array}{l}\text { LCT mean } \\
\text { score }\end{array}$ \\
\hline$M$ & R1 & 3.5 & 42.4 & \multirow{15}{*}{5.5} & \multirow{15}{*}{29.2} \\
\hline$M$ & R2 & 4.5 & 22.0 & & \\
\hline$M$ & R3 & 5.75 & 25.4 & & \\
\hline$M$ & R4 & 5.5 & 37.3 & & \\
\hline $\mathrm{M}$ & R6 & 5 & 32.2 & & \\
\hline $\mathrm{M}$ & R9 & 5.25 & 20.3 & & \\
\hline$M$ & R13 & 7 & 35.6 & & \\
\hline $\mathrm{M}$ & R14 & 6.25 & 37.3 & & \\
\hline$M$ & R18 & 4.25 & 16.9 & & \\
\hline $\mathrm{M}$ & R19 & 5.5 & 28.8 & & \\
\hline $\mathrm{M}$ & R20 & 6.25 & 30.5 & & \\
\hline $\mathrm{M}$ & R24 & 5.75 & 39.0 & & \\
\hline $\mathrm{M}$ & R26 & 5.75 & 23.7 & & \\
\hline $\mathrm{M}$ & R29 & 6.5 & 27.1 & & \\
\hline$M$ & R30 & 5.75 & 18.6 & & \\
\hline $\bar{F}$ & R5 & 4.75 & 27.1 & \multirow{15}{*}{5.8} & \multirow{15}{*}{28.0} \\
\hline $\mathrm{F}$ & R7 & 5 & 30.5 & & \\
\hline$F$ & R8 & 4.75 & 28.8 & & \\
\hline $\mathrm{F}$ & $\mathrm{R} 10$ & 5.5 & 32.2 & & \\
\hline $\mathrm{F}$ & R11 & 6.75 & 45.8 & & \\
\hline $\mathrm{F}$ & R12 & 7 & 35.6 & & \\
\hline $\bar{F}$ & R15 & 6.5 & 37.3 & & \\
\hline$F$ & R16 & 6 & 27.1 & & \\
\hline$F$ & R17 & 5.25 & 23.7 & & \\
\hline $\mathrm{F}$ & $\mathrm{R} 21$ & 5.5 & 23.7 & & \\
\hline $\mathrm{F}$ & R22 & 5.5 & 22.0 & & \\
\hline $\mathrm{F}$ & R23 & 5.75 & 25.4 & & \\
\hline $\mathrm{F}$ & R25 & 6 & 25.4 & & \\
\hline $\mathrm{F}$ & R27 & 6 & 10.2 & & \\
\hline $\mathrm{F}$ & R28 & 6.5 & 25.4 & & \\
\hline
\end{tabular}

Note. Speaking Proficiency: High $\square$ Moderate $\square$ Low $\$$

Table 5 illustrates the respondents' scores of SPT. $76.7 \%$ of respondents were moderate speakers with a mean ranging between $3.68-6.35 .20 .0 \%$ of them were of high level with a mean range of $6.36-9.00$ and only $3.3 \%$ fell under low category with a mean range of $1.00-3.67$.

Table 5. SPT Mean Score based on IELTS Scoring Rubric

\begin{tabular}{|c|c|c|c|c|c|}
\hline $\begin{array}{l}\text { IELTS } \\
\text { score }\end{array}$ & Proficiency & $\begin{array}{l}\text { IELTS Range } \\
\text { Scores }\end{array}$ & Frequency & $\begin{array}{c}\text { Percentage } \\
(\%)\end{array}$ & $\begin{array}{c}\text { Interpretation of } \\
\text { Mean Scores }\end{array}$ \\
\hline $8-9$ & High & \multirow{2}{*}{$6.36-9.00$} & \multirow{2}{*}{6} & \multirow{2}{*}{20} & \multirow{2}{*}{ High } \\
\hline $6-7$ & Moderate-high & & & & \\
\hline 5 & Moderate & $3.68-6.35$ & 23 & 76.7 & Moderate \\
\hline $3-4$ & Low-moderate & \multirow{2}{*}{$1.00-3.67$} & \multirow{2}{*}{1} & \multirow{2}{*}{3.3} & \multirow{2}{*}{ Low } \\
\hline $1-2$ & Low & & & & \\
\hline
\end{tabular}




\section{DISCUSSION}

The first question deals with students' knowledge of collocation and their speaking proficiency. It was hypothesized that the higher their knowledge of collocation the better their speaking proficiency is. To answer this question, the researcher administered two tests known as Speaking Proficiency Test (SPT) and Lexical Collocation Test (LCT). Scores from these tests were then correlated using Pearson's correlation coefficient. The results of the study revealed that the relationship was insignificant $(\mathrm{n}=30, \mathrm{r}=.192, \mathrm{p}>0.05)$. This could be attributed to their performance in the tests, as the majority of the respondents did not score well on LCT as well as SPT. The mean scores obtained for both tests were 28.6 and 5.6 respectively. This seems to contradict the findings of the study conducted by Sung (2003). The findings revealed that there was a significant correlation between the knowledge of lexical collocation and speaking proficiency. Likewise, a study conducted by Zhang (1993) on the knowledge of collocation and writing also revealed that there was a significant relationship between both variables. Similarly, in Al-Zahrani's (1998) study, it was found that there was a significant correlation between students' knowledge of collocation and their language proficiency. Although the variables involved are different, both studies are relevant to the discussion as the objective of these studies is similar to the current study which was to examine the relationship between the knowledge of collocation and the language skills which in this case were writing and language proficiency in general. The difference in the correlations could be attributed to the test construction and administration as there were many questions left unanswered by the respondents. This could be attributed to the lack of sufficient contextual clues to help them answer the questions. The setting and the process of selecting respondents might also account for their performance.

However, the scores on TLC to examine the knowledge of collocation in the current study seem to be consistent with Zhang's (1993) study which reported poor knowledge of collocation among non native speakers. Al-Sakran's (2011) study involving two groups of respondents from the ESL and EFL settings also yielded the same results. Both groups of students did poorly in the collocational test. Apart from being non native speakers, this similarity could also be attributed to the level of proficiency of these respondents. The abovementioned studies were conducted in the United States where the access and exposure to English is widespread [17, 18]. It is believed that exposure to the language helps learners acquire the language more efficiently and fluently. Along the same line, Normazidah, Koo and Hazita (2012: 41) state that "In learning a second language or a foreign language, research has established that it is utmost important that learners receive maximum support in terms of supportive and conducive learning environment as well as adequate, meaningful language experience". On the contrary, the respondents in this study did not have the same privilege as English is not widely used as a medium of interaction on a daily basis and instruction at schools in Malaysia especially in the rural area. Even in schools, some of the English teachers would resort to using Bahasa Malaysia to teach the English language at the expense of students' opportunity to get at least a formal exposure to the language. Besides, time allocated for the English lessons in Malaysian schools does not seem sufficient to allow them to speak good English. This is in tandem with Arshad and Hawanum (2010) in which they assert that:

Learning a second language is often a difficult task for many, especially for those who are not in the second language environment. In Malaysia, although English is widely used it is considered a second language after the national language, Bahasa Melayu. Additionally, the languages of the different ethnic groups in the country are also widely used in their respective communities. There are therefore few opportunities to naturally acquire the second language through interaction and conversation especially in the rural areas of the country. Hence, formal instruction in the classroom becomes the main means of learning the language, and in secondary schools, it tends to be limited to only five hours per week. During this limited period, teachers have to decide how to help their students become proficient in the language (164).

In addition, the respondents who were involved in Al-Zahrani's study (1998) comprised students majoring in English unlike the respondents of this study. Students majoring in English are considered advanced learners of English. It is expected that the collocation knowledge is better than 
the others. Moreover, most of the respondents of this study only obtained Band $3(n=24)$ in MUET and lacked exposure to English language, except for a few who use a mix of Malay and English at home or when they speak with friends. Most of them use their mother tongue at home which is Malay $(n=28)$. Furthermore, their use of English can be questioned in terms of accuracy. This would also affect their performance of the English language. There was also one student who scored poorly on SPT but scored well on LCT. This phenomenon is not uncommon as Malaysian education is strongly exam-oriented. Moreover, speaking skills are not emphasized in the national examinations except for Malaysian University English Test (MUET), which could be an explanation for student's poor performance in speaking. There are many students who manage to do well for instance writing their Sijil Pelajaran Malaysia (SPM) English paper, but find it difficult to converse in English owing to the lack of exposure, practice and motivation to speak the language.

\section{CONCLUSION}

The present study investigated the knowledge and use of collocation among Malay students of University Malaysia Kelantan. The main concern was to examine the relationship between students' lexical collocational competence and speaking proficiency. Besides problems with grammar, the students faced difficulties with the selection of lexical phrases, in this case, word combinations that could lead to their poor command of English language. It is believed that without this competence, communication will not be successful. This is due to the fact that the knowledge of collocation "has a huge impact on many aspects of language processing, comprehension and use" [15]. As this knowledge increases learners' vocabulary, their overall language proficiency will automatically improve $[6,9,11]$.

This study was carried out in response to the need to address this specific problem among these students, so that the knowledge and the use of collocation in particular and the command of English in general can be improved. Hence, a better command of English. It was found that there was no significant correlation between students' knowledge of lexical collocation and their speaking proficiency $(\mathrm{n}=30, \mathrm{r}=.192, \mathrm{p}>0.005)$. This finding was inconsistent with the previous research conducted by Sung (2003). This inconsistency could be attributed to various factors. The most noticeable factor was the exposure to the target language and the first language interference. Sung's (2003) study was conducted in the United States involving participants who had stayed there for a longer period of time. This study however was conducted in Malaysia, a non English speaking country. Hence, the exposure to the language was scarce. This study also revealed that the majority of the respondents did not perform well in LCT $(\mathrm{M}=28.58)$ which was similar to Zhang's (1993) and Al-Sakran's (2011) studies.

\section{References}

[1] Alsakran, R.A. (2011). The productive and receptive knowledge of collocations by advanced Arabic-speaking ESL/EFL learners. (Master's Thesis, Colorado State University, 2011). ProQuest, UMI Dissertations Publishing, 1497925.

[2] Al-Zahrani, M.S. (1998). Knowledge of English lexical collocations among male Saudi college students majoring in English at a Saudi University. (Doctoral dissertation, Indiana University of Pennsylvania, 1998). UMI Dissertation.

[3] Arshad Abd Samad, Hawanum Hussein. (2010). Teaching grammar and what student errors in the use of the English language auxhillary 'be' can tell you. The English Teacher Vol. XXXIX: 164-178.

[4] Benson, M., Benson, E., \& Elson, T. (1986). The BBI combinatory dictionary of English. Amsterdam: John Benjamin. 
[5] Darvishi, S. (2011). The Investigation of collocational errors in university students' writing majoring in English. In International Conference on Education, Research and Innovation 2011, IPEDR vol.18 IACSIT Press. Singapore.

[6] Ellis, R. (1997). Second language acquisition. New York: Oxford University Press.

[7] Erman, B., Warren, B. (2000). The idiom principle and the open choice principle. Text 20: 2962.

[8] Fan, M. (2009). An exploratory study of collocational use by ESL students - A task based Approach. Direct Science System, 37, 110-123.

[9] Hill, J. (2000). Revisiting priorities: from the grammar failure to collocational success. In L. Micheal (Ed.), Teaching collocation: further development in the lexical approach. England: Language Teaching Publication.

[10]Kuo, C.L. (2009). An analysis of the use of collocation by intermediate EFL college students in Taiwan. ARECLS, 6, 141-155.

[11]Lewis. M. (2000). Learning in the Lexical Approach. In L. Micheal (Ed.), Teaching collocation: further development in the lexical approach. England: Language Teaching Publication.

[12]Lewis, M. (2002). Implementing the lexical approach putting theory into practise. USA. Language teaching Publications Series.

[13]Nation, P. (2001). Learning vocabulary in another language. Cambridge: Cambridge University Press.

[14]Normazidah Che Musa.,Koo, Y.L., Hazita Azman. (2012). Exploring English language leaerning and teaching in Malaysia. GEMA Online ${ }^{\mathrm{TM}}$ Journal of Language Studies 35 Volume 12(1), Special Section.

[15] Shehata, A. (2008). L1 influence on the reception and production of collocations by advanced ESL/EFL Arabic learners of English (Master's thesis, The College of Arts and Sciences of Ohio University, 2008).

[16] Schmitt, N. (ed.) (2004). Formulaic sequences: Acquisition, processing and use. Amsterdam: John Benjamins.

[17] Sung, J. (2003). English lexical collocation and their relation to spoken fluency of adult nonnative speaker (Doctoral dissertation, Indiana University of Pensylvania, 2003).

[18]Zhang, X. (1993). English collocations and their effect on the writing of native and non-native college freshmen (Doctoral dissertation, Indiana University of Pensylvania, 1993). Dissertation Abstracts International, 54 (3), 910 A. 